EDITORIAL

\title{
Women in cardiology: a UK perspective
}

\author{
A D Timmis, K M English
}

\begin{abstract}
Women are particularly under-represented in cardiology in the UK, even though women outnumber men in admissions to medical school. Could this disparity be detrimental to the specialty in this country?
\end{abstract}

I $\mathrm{n}$ the last 10 years women entering UK medical schools have for the first time come to outnumber men. Despite this, women remain under-represented in many hospital specialties, particularly cardiology where they comprise only $16.8 \%$ of trainees and $7.4 \%$ of consultants. ${ }^{1}$ Last year the British Cardiac Society (BCS) established a working group to determine whether the continuing male predominance among cardiologists is a cause for concern and, in particular, whether it might be acting to the detriment of the specialty in this country. The working group's report, which appears in this issue of Heart," states that "the failure of cardiology to attract women when the gender ratio of medical undergraduates is approximately balanced, indicates that a substantial proportion of the talent pool is being lost to other specialties", and is unequivocal in concluding that "if [the failure of cardiology to attract women] is not corrected it will prove increasingly difficult to maintain high standards of cardiological practice and research". The working group's report identified reasons for this failure and offered strategies for redressing the gender balance that are summarised in the table of action points.

\section{CAREER ASPIRATIONS AND CHOICES}

A key observation was the contrast between the career aspirations and subsequent career choices of female graduates. Thus in one study ${ }^{3}$ women accounted for $28 \%$ of those targeting a career in cardiology - the most popular specialty preference-yet Deanery data show that they currently account for only $17 \%$ of cardiology trainees nationwide, falling to $8 \%$ in London. No evidence was found of gender discrimination at the point of selection for cardiology training programmes and the working group concluded that many women were being "turned off" the specialty early in their medical careers. Of course, this may reflect an informed choice that women make having observed the long, family unfriendly hours that cardiology trainees often have to work, coupled with the unavailability of childcare facilities in most hospitals in this country. Indeed, it is noteworthy that childcare is the reason most commonly cited-almost invariably by women-for temporarily leaving the workforce. ${ }^{4}$ Will cardiology become more family

friendly for both women and men with introduction of the European Working Time Directive? Almost certainly yes, but the working group recognised that this is unlikely to provide sufficient spare time for the early years of childcare, emphasising that flexible training opportunities will remain the most important mechanism of fulfilling this requirement for potential applicants to cardiology training programmes, particularly women.

Improving the provision of flexible training opportunities must be the primary mechanism of attracting more women into cardiology. The large majority of flexible trainees are women, mostly in specialties such as anaesthetics, psychiatry, and paediatrics, but they account for only a tiny handful of cardiology trainees. Flexible trainees are commonly felt to be more difficult to accommodate within training programmes, but this issue is surmountable (as has been demonstrated by other specialties), particularly in a sessionally based specialty like cardiology. Job sharing is another attractive but currently unrealistic solution to this problem, being dependent upon a critical mass of local applicants who might wish to train flexibly. Whether flexible training posts are independent or shared, however, more supernumerary funding is the key to increasing their availability, bearing in mind that new posts will attract high quality applicants only if they offer equivalent training to their full time counterparts. More funding will be effective only if it attracts new applicants wishing to train flexibly, who would otherwise not have applied to cardiology.

Cardiology is a specialty which has not, at least thus far, courted the potential inconvenience of flexible trainees, there being no shortage of applicants, mostly men, prepared to work full time. To improve this situation, the working group recommended that information on flexible training be provided to all trainees who should be encouraged on appointment or in appraisal to declare, as necessary, their need for it. It also recommended that this be backed up by the appointment by Specialist Training Committees of flexible training representatives to attend regular meetings with the regional Associate Dean for Flexible Training.

\section{PART TIME WORKING}

Arguments for increasing flexible training opportunities apply with equal force to part time consultant posts, which the working group saw as vital for increasing recruitment of female cardiologists. A questionnaire circulated by the working group to female cardiology trainees indicated that a substantial proportion was considering working part time upon completion 
of training, and failure to accommodate these doctors could cause considerable workforce problems. Part time opportunities will undoubtedly increase with the diminishing commitment of cardiologists to general medical take and the adoption of "programmed activities" whereby job plans can be more closely aligned to reimbursement within the new consultant contract. However, the success of these jobs will depend not only on the provision of imaginative and stimulating job plans, but also on the attitudes of those who continue to work full time. It seems that currently it is professionally acceptable to spend some sessions away from direct patient contact in the National Health Service (NHS) if one is working either in support of a professional body or in the private sector, but not if that time is spent caring for one's family. Part time working should be recognised as a "career friendly" option with the potential to fulfil the needs of both men and women to manage a healthy and productive balance between work and life outside. ${ }^{5}$

It is not only the difficulties of balancing work and family life that deter many women from entering cardiology, but also some of the attitudes that pervade this male dominated specialty. For example, there is a widely held perception that women are discouraged from involvement in some of the popular subspecialties, particularly coronary intervention and electrophysiology. To some extent this may reflect concerns women have about radiation exposure and fetal risk but, after reviewing the evidence, the working group concluded that these are largely unfounded and that for women who are (or wish to become) pregnant there is a large safety margin to continue interventional work in the catheter laboratory, provided appropriate protective measures are taken. More concerning and equally unfounded is any suggestion that the manual dexterity component of cardiological practice provides a credible reason for deterring women from the specialty. Nevertheless, the working group accepted that onerous on-call commitments of interventional cardiologists can have a negative impact on family life for both men and women, particularly with the impending introduction of primary angioplasty on-call rotas; however, this might be tempered by the need to develop partial shift work in order to satisfy the requirements of the European Working Time Directive. Indeed, it is possible to speculate that this would facilitate incorporation of part time consultants into the interventional cardiology service, paradoxically making it a more attractive subspecialty option for women.

\section{SEXISM}

The working group did not shy away from discussing sexism and gender based discrimination as a potential contributor to the under-representation of women in cardiology. Nearly half the trainees who responded to the questionnaire reported gender bias at work and considered that career prospects were worse for women than men. Some appalling examples of this were provided. Nevertheless, there is no evidence of gender bias in recruitment to cardiology training programmes and, as more women become consultants, it is reasonable to assume that the working environment and career prospects for women will improve. It was a major conclusion of the report that more female role models within the specialty would have a profoundly beneficial effect on the working environment and career prospects for women. Meanwhile the recommendation was for the appointment of mentors locally and nationally to encourage women to apply for cardiology training programmes, help retain them within those programmes, and provide independent "off-site" help and advice in the event of unwelcome gender-at-work issues.
Action points

- Mentors for women in cardiology

- Trust based

- Deanery based

- Specialty based (British Cardiac Society)

- Encourage flexible training

- STC based flexible training representatives

- Look for supernumerary funding from Deaneries

- Look for job share opportunities

- Establish more part time consultant posts

- Improve access for women to popular subspecialtiesfor example, intervention

- Refuse to tolerate sexism or gender based discrimination in the work place

The response of the BCS to the working group's report was immediate and decisive. Approval was given for the appointment to Council of a new female member to represent women's interests, the Society's Articles of Association were amended accordingly, and within three months of receipt of the report the election ballot was in progress. Meanwhile, the report was submitted to Heart to provide further publicity for its findings. There could be no better reflection of the importance the BCS attaches to the report and to attracting more women into the specialty.

Finally, it is salutary to note that nearly all respondents to the questionnaire circulated to female trainees and consultants were adamant that they would recommend a career in cardiology to a female senior house office considering entering the specialty. This led the working group to conclude that despite the gender related difficulties that many of the respondents reported, it is clear that a career in cardiology can be as fulfilling for women as for men. Indeed progressively more women are being selected for training programmes and it is hoped that this trend will continue given the small excess of women now in medical school and junior hospital jobs. The action points recommended by the working group will facilitate this process and in doing so will encourage the most talented individuals, regardless of gender, to enter cardiology in this country, invigorating the specialty and helping to maintain the highest standards of clinical practice, teaching and research.

\section{Authors' affiliations}

A D Timmis, London Chest Hospital, London, UK

K M English, Yorkshire Heart Centre, Leeds General Infirmary, Leeds, UK

\section{REFERENCES}

1 Census of Consultant Physicians in the UK, 2002. The Federation of the Royal Colleges of Physicians of the United Kingdom, 2002. www.rcplondon.ac.uk.

2 Timmis AD, Baker C, Banerjee S, et al. Women in UK cardiology: report of a Working Group of the British Cardiac Society. Heart 2005;91:283-9.

3 Lambert T, Goldacre M, Parkhouse J. Career preferences and their variation by medical school among newly qualified doctors. Health Trends 1996:28:135-44.

4 BMA Health Policy and Economic research Unit. BMA Cohort Study of Medical Graduates 1995, 5th Report. London: BMA, 2000.

5 Coyle A. Women and flexible working in the NHS, Equal Opportunities Commission Working Paper Series No.9. 2003. 